\title{
Modeling and Analysis of Doubly Fed Wind Power Generation System
}

\author{
WANG Zhijie ${ }^{1}$, LIU Sanming ${ }^{1}$, LIU Tianyu ${ }^{1}$, WANG Dongwei ${ }^{1}$, DU Bin ${ }^{1}$, \\ HUANG Qiyuan $^{1}$, JIANG Xiucheng ${ }^{2}$,SHENG Gehao ${ }^{2}$ \\ ${ }^{1}$ School of Electrical Engineering,Shanghai Dianji University,Shanghai 200240,China; \\ ${ }^{2}$ School of Electrical Engineering,Shanghai Jiaotong University,Shanghai 200240,China; \\ E-mail1:wzjsdstu@163.com, E-mail2: 1104707836@qq.com
}

\begin{abstract}
Keywords: Doubly fed wind generator; modeling analysis; low voltage operation; optimal control strategy
\end{abstract}

Abstract. In this paper, the steady state and transient model of the DFIG system are analyzed. It is concluded that the PI controller parameters and stator transient current are influenced by different parameters of the system, including resistance value, generator rotor inductance or sag magnitude of power grid voltage, etc. Then the steady state and transient model of doubly fed wind power generation system are analyzed. It is concluded that there are two ways to improve the low voltage operation of the doubly fed wind power generation system. One is to use the optimal control strategy to improve the control of the current inner loop of the doubly fed wind power generation system; The other is that when the power grid voltage has the drop fault, it can be considered to increase the Crowbar protection circuit to consume excess energy in the DC side, this way can solve the problem of high DC bus voltage caused by unbalanced power.

\section{Structure of double fed wind power generator}

Firstly, the double fed wind power generator rotor is connected to the converter. Secondly, it is connected to the power grid through the converter. In the end, the stator is directly connected to the power grid. The structure of doubly fed wind power generator is shown in Figure 1.

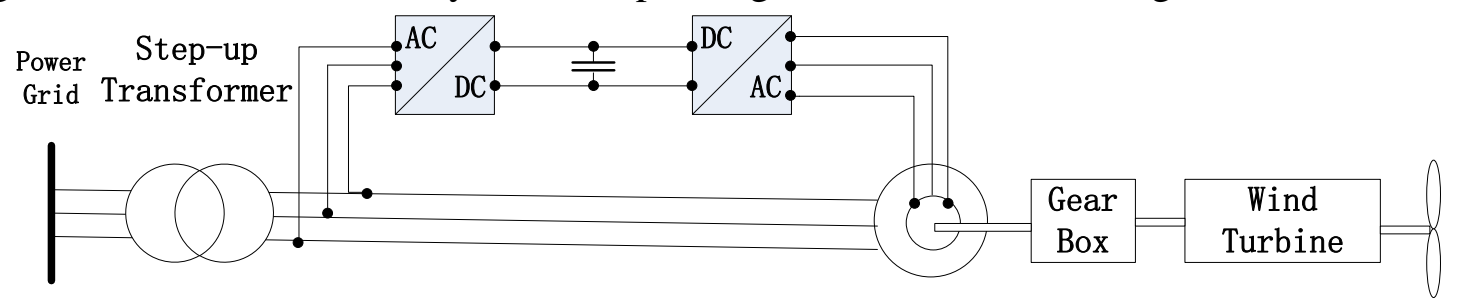

Fig. 1 the structure of doubly fed wind power generator

\section{Model and analysis of doubly fed induction generator system}

The steady state and transient model of a doubly fed induction generator (DFIG) wind power generation system are established. Then the low voltage operation of DFIG system is analyzed further. By deriving the steady-state mathematical model of DFIG system, The vector control chart of generator side converter in DFIG system is obtained. On the basis of this, the PI controller parameters are obtained by using the internal model control box to add the active damping, this can improve the control stability of doubly fed wind power generation system. According to DFIG generator's transient circuit equation, A system model of doubly fed wind generator is established, The expression of transient current of doubly fed wind power generation system is obtained, this can provide theoretical guidance for the study of low voltage operational capability[1,2,3,4].

Steady state model and control method of doubly fed induction generator wind power generation system

In order to study the control method of doubly fed wind power generation system, the mathematical model of DFIG system is established in the synchronous rotating coordinate system. 


$$
\left[\begin{array}{l}
\mathrm{u}_{\mathrm{ds}} \\
\mathrm{u}_{\mathrm{qs}} \\
\mathrm{u}_{\mathrm{dr}} \\
\mathrm{u}_{\mathrm{qr}}
\end{array}\right]=\left[\begin{array}{cccc}
\mathrm{pL}_{\mathrm{s}}+\mathrm{R}_{\mathrm{s}} & -\mathrm{w}_{1} \mathrm{~L}_{\mathrm{s}} & \mathrm{pL}_{\mathrm{m}} & -\mathrm{w}_{1} \mathrm{~L}_{\mathrm{m}} \\
\mathrm{w}_{1} \mathrm{~L}_{\mathrm{s}} & \mathrm{pL}_{\mathrm{s}}+\mathrm{R}_{\mathrm{s}} & \mathrm{w}_{1} \mathrm{~L}_{\mathrm{m}} & \mathrm{pL}_{\mathrm{m}} \\
\mathrm{pL}_{\mathrm{m}} & -\left(\mathrm{w}_{1}-\mathrm{w}_{\mathrm{r}}\right) \mathrm{L}_{\mathrm{m}} & \mathrm{pL}_{\mathrm{r}}+\mathrm{R}_{\mathrm{r}} & -\left(\mathrm{w}_{1}-\mathrm{w}_{\mathrm{r}}\right) \mathrm{L}_{\mathrm{r}} \\
\left(\mathrm{w}_{1}-\mathrm{w}_{\mathrm{r}}\right) \mathrm{L}_{\mathrm{m}} & \mathrm{pL}_{\mathrm{m}} & \left(\mathrm{w}_{1}-\mathrm{w}_{\mathrm{r}}\right) \mathrm{L}_{\mathrm{r}} & \mathrm{pL}_{\mathrm{r}}+\mathrm{R}_{\mathrm{r}}
\end{array}\right]\left[\begin{array}{l}
\mathrm{i}_{\mathrm{ds}} \\
\mathrm{i}_{\mathrm{qs}} \\
\mathrm{i}_{\mathrm{dr}} \\
\mathrm{i}_{\mathrm{qr}}
\end{array}\right] .
$$

In the formula, $\mathrm{u}$ and $\mathrm{i}$ represent the voltage and current respectively; The subscript $\mathrm{r}$ and $\mathrm{s}$ represent the stator and rotor components respectively; The subscript $\mathrm{d}$ and q represent the component of $\mathrm{d}$ and $\mathrm{q}$ axis respectively; $\mathrm{R}$ and $\mathrm{L}$ represent the amount of inductance and resistance respectively; The $\mathrm{p}$ represents the differential operator; $w_{1}$ represents the rotating speed of synchronous coordinate. $w_{r}$ represents the rotor angular velocity.

According to the definition of motor magnetic flux:

$$
\left\{\begin{array}{l}
\psi_{d s}=L_{s} i_{d s}+L_{m} i_{d r} \\
\psi_{q s}=L_{s} i_{q s}+L_{m} i_{q r}
\end{array}\right.
$$

In the formula (1), make the stator flux linkage become the $\mathrm{d}$ axis of the rotating coordinate system: $\psi_{\mathrm{qs}}=0$ and $\omega_{s}=\omega_{1}-\omega_{r}$, then put formula (2) into formula (1), leading to:

$$
\left\{\begin{array}{l}
u_{d r}=\left(L_{r}-\frac{L_{m}^{2}}{L_{s}}\right) p i_{d r}+r_{r} i_{d r}-\omega_{s}\left(L_{r}-\frac{L_{m}^{2}}{L_{s}}\right) i_{q r}+\frac{L_{m}}{L_{s}} p \psi_{d s} \\
u_{q r}=\left(L_{r}-\frac{L_{m}^{2}}{L_{s}}\right) p i_{q r}+r_{r} i_{q r}-\omega_{s}\left(L_{r}-\frac{L_{m}^{2}}{L_{s}}\right) i_{d r}+\omega_{s} \frac{L_{m}}{L_{s}} \psi_{d s}
\end{array}\right.
$$

The formula (3) shows that the generator can be decoupled control, by feedforward compensating for the rotor voltage. The feedforward compensatation is $e_{d r}$ and $e_{q r}$.

$$
\left\{\begin{array}{l}
e_{d r}=\omega_{s}\left(L_{r}-\frac{L_{m}^{2}}{L_{s}}\right) i_{q r}-\frac{L_{m}}{L_{s}} p \psi_{d s} \\
e_{q r}=-\omega_{s}\left(L_{r}-\frac{L_{m}^{2}}{L_{s}}\right) i_{d r}-\omega_{s} \frac{L_{m}}{L_{s}} \psi_{d s}
\end{array} .\right.
$$

Put formula (4) into formula (3), then it can get the relationship between voltage and current.

$$
\left\{\begin{array}{l}
\left(L_{r}-\frac{L_{m}^{2}}{L_{s}}\right) p i_{d r}=-r_{r} i_{d r}+u_{d r}^{*} \\
\left(L_{r}-\frac{L_{m}^{2}}{L_{s}}\right) p i_{q r}=-r_{r} i_{q r}+u_{q r}^{*}
\end{array} .\right.
$$

The result shows that the current loop control performance of the doubly fed wind power generation system is improved by coupling with the feed forward compensation term. [5,6]Then the block diagram of current loop control in DFIG system is shown in Figure 2. 


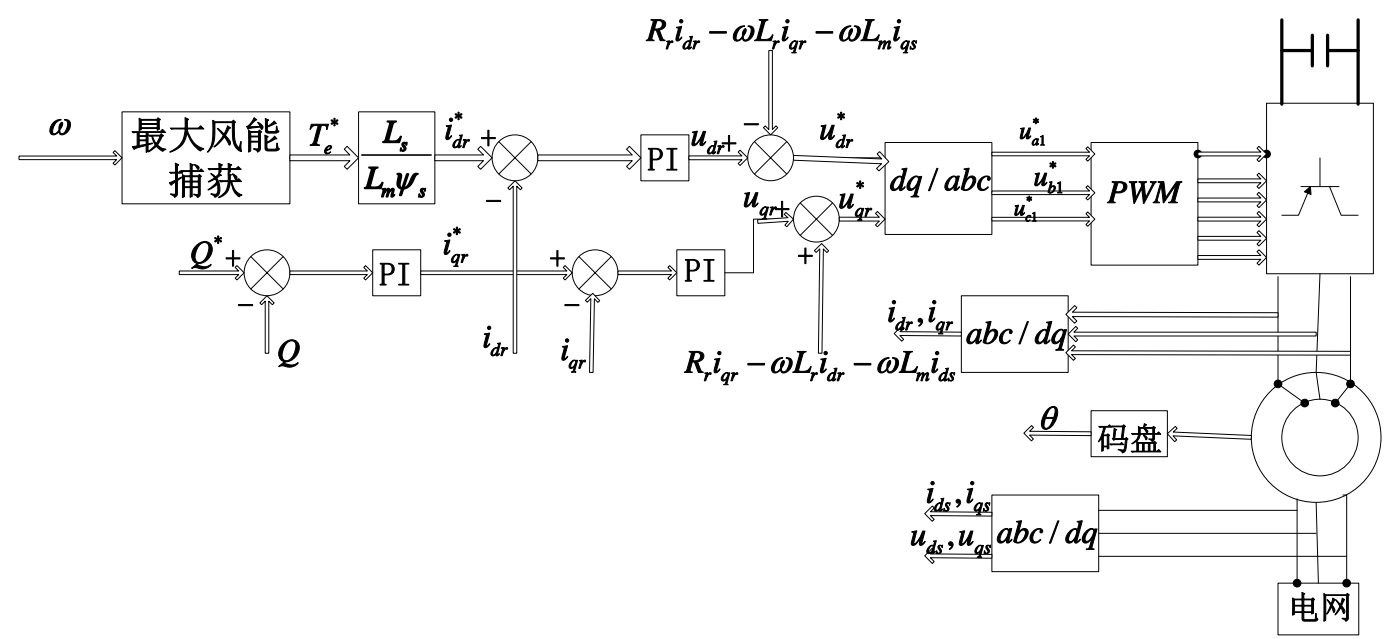

Fig. 2 The block diagram of current loop control in DFIG system

Using the method of internal model control (IMC) and active damping, the parameters $\left(k_{i} 、 k_{p}\right)$ of PI controller are obtained.

$$
\left\{\begin{array}{l}
k_{i}=\left(\alpha_{c} \ln 9\right)^{2}\left(L_{r}-\frac{L_{m}^{2}}{L_{s}}\right) \\
k_{p}=\left(\alpha_{c} \ln 9\right)\left(L_{r}-\frac{L_{m}^{2}}{L_{s}}\right)
\end{array} .\right.
$$

Then the expression of $\mathrm{d}$ and $\mathrm{q}$ axis current PI controller is obtained.

$$
\frac{U(s)}{E(s)}=\frac{k_{i}}{s}+k_{p}
$$

In the formula, $\mathrm{U}(\mathrm{s})$ is the output of the PI controller; E (s) is the input of the PI controller.

The actual controller needs to be discretized with an ideal controller. The discretization method is:

$$
U(n)=k_{p} U(n-1)+T_{S I} k_{i}[E(n)-E(n-1)]
$$

In the formula, ${ }^{T_{S I}}$ is the system sampling time; ${ }^{k_{p}} 、 k_{i}$ is consistent with the PI parameter in the continuous system; $U$ (n) is the output sequence; $E(n)$ is the input sequence.

When bandwidth of PI controller is $\alpha_{c}=100 \mathrm{~Hz}$, Switching frequency is $5 \mathrm{kHz}$, $L_{r}-L_{m}^{2} / L_{s}=7.90 \times 10^{-3}$, According to the formula (8) :

$$
\left\{\begin{array}{l}
k_{i}=(100 \times \ln 9)^{2} \times 0.0079 \times 0.0002=0.0763 \\
k_{p}=(100 \times \ln 9) \times 0.0079=1.736
\end{array}\right.
$$

\section{Transient model and control method of DFIG wind power generation system}

When the power grid voltage sags, the output voltage of the DFIG wind power system is reduced, and the grid current changes little, which leads to the decrease of output power; but there is no obvious change in the output power of the wind turbine; the result is that the input and output power is not balanced, the excess energy is not transferred to the power grid, the whole accumulation in the DC bus, which results in a sharp rise in DC bus voltage.If the DC bus is connected to the direct unloading resistance, the excess energy can be consumed. Based on the superposition principle, the transient model of DFIG in voltage sag fault is derived. Stator three phase voltage symmetrical drop is a process that it is added a voltage in the stator side, the magnitude of the voltage amplitude is equal to 
the amplitude of the original voltage amplitude and the direction is opposite[7,8]. Assume that Space vector with stator short circuit current is:

$$
i_{s}=i_{s 0}+i_{s 1}
$$

In the formula, $i_{s 0}$ is space vector of stator current before voltage drop; is Stator current space vector generated by reverse phase voltage of stator end.

Assume that the stator voltage space vector is $u_{s}=-j U_{m} e^{i\left(\omega_{s} t+\varphi\right)}$, In the rotor coordinate system, $u_{s}^{\prime}=u_{s} e^{-i \omega_{r} t}=-j U_{m} e^{i\left(\omega_{s} t+\varphi\right)}$, The current vector before stator voltage drop is $i_{s 0}^{\prime}$.

$$
i_{s 0}^{\prime}=\frac{u_{s}^{\prime}}{R_{s}+j \omega_{1} L_{s}}=\frac{-j U_{m} e^{j\left(\omega_{s} t+\varphi\right)}}{R_{s}+j X_{s}}
$$

In the formula, $X_{s}$ is the stator reactance; $X_{s}=\omega_{1} L_{s}=X_{s \sigma}+X_{m}, X_{s \sigma}$ is stator leakage reactance, $X_{m}$ is excitation reactance, $\omega_{1}$ is Stator synchronous rotating angular velocity, $\omega_{r}$ is Rotor rotating electric angular velocity, $\omega_{s}$ is slip angle velocity; $X_{s} \gg R_{s}$, commonly, Therefore the formula (11) can be approximated as:

$$
i_{s 0}^{\prime} \approx-\frac{U_{m} e^{j\left(\omega_{s} t+\varphi\right)}}{X_{s}}
$$

In the rotor coordinate system, when the initial value of the stator and rotor flux is 0 , Laplace transform of stator voltage equation is:

$$
A U_{s 1}^{\prime}=R_{s} I_{s 1}^{\prime}+\left(s+j \omega_{1}\right) \psi_{s 1}^{\prime}=\left[R_{s}+\left(s+j \omega_{1}\right) L_{s}(s)\right] I_{s 1}^{\prime}
$$

$L_{s}(s)$ is operation inductance of stator in rotor coordinate system, $L_{s}(s)=L_{s}\left(1+s T_{r}^{\prime}\right) /\left(1+s T_{r}\right)$, $T_{r}$ and $T_{r}^{\prime}$ are the the time constant and the transient time constant of the rotor; then $I_{s 1}^{\prime}$ can be obtained.

$$
I_{s 1}^{\prime}=\frac{A U_{s 1}^{\prime}}{R_{s}+\left(s+j \omega_{1}\right) L_{s}(s)}=\frac{j A U_{m} e^{j \varphi}}{\left(s-j \omega_{s}\right)\left[\alpha+s+j \omega_{1}\right] L_{s}(s)}
$$

$A U_{s 1}^{\prime}$ is the Laplace transform of $-A U_{s}^{\prime}, U_{s 1}^{\prime}=L\left[j A U_{m} e^{j\left(\omega_{s}+\varphi\right)}\right]=j A U_{m} e^{j \varphi} /\left(s-j \omega_{s}\right), \alpha$ is attenuation coefficient of stator DC component, $\alpha=R_{s} / L_{s}(s) \approx R_{s} / L_{s}^{\prime}$.

Make the reciprocal of the computing inductance $1 / L_{s}(s)$ become a partial fraction, then:

$$
I_{s 1}^{\prime}=\frac{j A U_{m} e^{j \varphi}}{\left(s-j \omega_{s}\right)\left[\alpha+s+j \omega_{1}\right]}\left[\frac{1}{L_{s}}+\left(\frac{1}{L_{s}^{\prime}}-\frac{1}{L_{s}}\right) \frac{s T_{r}^{\prime}}{1+s T_{r}^{\prime}}\right]
$$

Get the inverse Laplace transform of formula (15):

$$
i_{s 1}^{\prime}=L^{-1}\left[I_{s 1}^{\prime}\right]=\frac{j A U_{m} e^{j\left(\omega_{s} t+\varphi\right)}}{L_{s}\left(\alpha+j \omega_{r}\right)}\left[1-e^{-\left(\alpha+j \omega_{1}+j \omega_{s}\right) t}\right]+\left(\frac{1}{L_{s}^{\prime}}-\frac{1}{L_{s}}\right) L^{-1}\left[\frac{j A U_{m} e^{j \varphi}}{\left(s-j \omega_{s}\right)\left(\alpha+s+j \omega_{1}\right)} \frac{s T_{r}^{\prime}}{1+s T_{r}^{\prime}}\right]
$$

Commonly, $\alpha<<\omega_{\mathrm{r}},-\frac{1}{\mathrm{~T}_{\mathrm{r}}^{\prime}}+\alpha<<\omega_{\mathrm{r}},\left(\mathrm{s}-\mathrm{j} \omega_{\mathrm{s}}\right)\left(\alpha+\mathrm{s}+\mathrm{j} \omega_{1}\right) \approx \mathrm{s}\left(\mathrm{s}+\alpha+\mathrm{j} \omega_{\mathrm{r}}\right)$, so the formula (16) can be simplified:

$$
i_{s 1}^{\prime} \approx \frac{A U_{m} e^{j\left(\omega_{s} t+\varphi\right)}}{X_{s}}\left[1-e^{-\left(\alpha+j \omega_{1}+j \omega_{s}\right) t}\right]+A U_{m} e^{j \varphi}\left(\frac{1}{X_{s}^{\prime}}-\frac{1}{X_{s}}\right)\left[e^{-\frac{1}{T_{r}^{\prime}}}-e^{-\left(\alpha+j \omega_{r}\right) t}\right]
$$

When the induction motor load is light, it is considered $\omega_{\mathrm{r}} \approx \omega_{1}$, then:

$$
i_{s}^{\prime}=i_{s 0}^{\prime}+i_{s 1}^{\prime} \approx(A-1) \frac{U_{m} e^{j\left(\omega_{s} t+\varphi\right)}}{X_{s}}-\frac{A U_{m} e^{j \varphi}}{X_{s}^{\prime}} e^{-\alpha t}+A U_{m} e^{j \varphi}\left(\frac{1}{X_{s}^{\prime}}-\frac{1}{X_{s}}\right) e^{-\frac{1}{T_{r}^{\prime}}}
$$


Finally, the space vector of stator current in the stator coordinate system is:

$$
\mathrm{i}_{\mathrm{s}}=\mathrm{i}_{\mathrm{s}} \mathrm{e}^{\mathrm{j} \omega_{\mathrm{r}} \mathrm{t}}=(\mathrm{A}-1) \frac{\mathrm{U}_{\mathrm{m}} \mathrm{e}^{\mathrm{j}\left(\omega_{1} \mathrm{t}+\varphi\right)}}{\mathrm{X}_{\mathrm{s}}}-\frac{A U_{\mathrm{m}} \mathrm{e}^{\mathrm{j} \varphi}}{\mathrm{X}_{\mathrm{s}}^{\prime}} \mathrm{e}^{-\alpha \mathrm{t}}+\mathrm{AU}_{\mathrm{m}} \mathrm{e}^{\mathrm{j} \varphi}\left(\frac{1}{\mathrm{X}_{\mathrm{s}}^{\prime}}-\frac{1}{\mathrm{X}_{\mathrm{s}}}\right) \mathrm{e}^{-\frac{1}{\mathrm{~T}_{\mathrm{r}}^{\prime}}} \mathrm{e}^{\mathrm{j} \omega_{\mathrm{r}} \mathrm{t}}
$$

The stator current of A phase is:

$$
i_{A}=\operatorname{Re}\left(i_{s}\right)=(A-1) \frac{U_{m}}{X_{s}} \cos \left(\omega_{1} t+\varphi\right)-\frac{A U_{m}}{X_{s}^{\prime}} e^{-\alpha t} \cos \varphi+A U_{m}\left(\frac{1}{X_{s}^{\prime}}-\frac{1}{X_{s}}\right) e^{-\frac{1}{T_{r}}} \cos \left(\omega_{r} t+\varphi\right)
$$

According to the formula (20), it can be seen that the stator current is composed of three parts: $(A-1) \frac{U_{m} e^{j\left(\omega_{1}+\varphi\right)}}{X_{s}}$ is the steady state component of the stator current, which is determined by the magnitude of the voltage drop. $\frac{\mathrm{AU}_{\mathrm{m}} \mathrm{e}^{\mathrm{j} \varphi}}{\mathrm{X}_{\mathrm{s}}^{\prime}} \mathrm{e}^{-\alpha t} \cos \varphi$ is the magnitude of the transient current which is determined by the phase angle $\varphi$ of the short circuit. This component is attenuated by the stator time constant $T_{a}, \mathrm{~T}_{\mathrm{a}}=1 / \alpha ; \mathrm{AU}_{\mathrm{m}}\left(\frac{1}{\mathrm{X}_{\mathrm{s}}^{\prime}}-\frac{1}{\mathrm{X}_{\mathrm{s}}}\right) \mathrm{e}^{-\frac{1}{\mathrm{~T}_{\mathrm{r}}}} \cos \left(\omega_{\mathrm{r}} \mathrm{t}+\varphi\right)$ is the $\mathrm{AC}$ component, which accounts for the majority of the transient current, and the transient decay time constant $T_{r}^{\prime}$.

By analyzing the transient model of doubly fed wind power system, the stator transient current can be influenced by the setting of different parameters in the system, including resistance value, generator rotor inductance or power grid voltage sag magnitude, etc. When it happens voltage sag, by changing the settings of these parameters, the influence of the unstable operation of the DFIG system can be weaken. But the rotor current is much less than that of the stator current, it is more feasible to change the generator rotor resistance with respect to the change of stator and rotor inductance. In order to reduce the transient current effectively, the rotor resistance value can be increased, which can result in the normal operation of the machine side converter and achieve the low voltage ride through the DFIG unit.

\section{Conclusion}

In this paper, DFIG structure is introduced, the steady state and transient model of DFIG system are analyzed. Based on the derivation of DFIG system model, the parameters of the PI controller can be obtained; By analyzing the transient model of doubly fed wind power generation system, it is concluded that the stator transient current can be influenced by the setting of different parameters in the system, including the resistance value, the generator rotor inductance or the power grid voltage sag amplitude, etc..Then the steady state and transient model of doubly fed wind power generation system are analyzed. It is concluded that there are two ways to improve the low voltage operation of the doubly fed wind power generation system. One is to use the optimal control strategy to improve the control of the current inner loop of the doubly fed wind power generation system;The other is that when the power grid voltage has the drop fault, it can be considered to increase the Crowbar protection circuit to consume excess energy in the DC side, this way can solve the problem of high DC bus voltage caused by unbalanced power.

\section{Acknowledgements}

This work was financially supported by the National Natural Science Fund Project of China (51477099, 11304200), The Natural Science Fund Project of Shanghai (15ZR1417300, 14ZR1417200), The Education Innovation Fund Projects of Shanghai(14YZ157, 15ZZ106), The Science Fund Projects of Minhang, Shanghai(2014MH166). 


\section{References}

[1] Li Jianlin,Hu Changsheng,Wang Liqiao,etc.APF Based on Multilevel Voltage Source Cascade Converter with Carrier Phase Shifted SPWM [C]. TENCON 2003. Conference on Convergent Technologies for Asia-Pacific Region, Volume: 1, 15-17 Oct. 2003 Vol. 1, 264-267.

[2] David-p, Molenaar, SjoerdDijkstra. State-of-the-art of Wind Turbine Desigh Codes: Mean Feature Overview for cost-effective generation[J].Wind Engineering, Jan.2010..

[3] Thomas Ackermann, Lennart soder. Wind energy technology and current status: a review[J]. Renewable and Sustainable Energy Reviews,2010,12(4):315-374.

[4] Li H, Chen Z. Overview of different wind generator systems and their comparisons. IET Renewable Power Generation[J], 2008, 2(2): 123-138.

[5] R.Esmaili, and L.Xu, and D.K.Nichols, "A New Control Method of Permanent Magnet Gnerator for Maximum Power Tracking in Wind Turbine Application," in Proc. 2005 IEEE Power Engineering Society General Meeting[C], pp.2090-2095.vol.3.

[6] Seung-Ho Song, Shin-il Kang and Nyeon-Kun Hahm, "Implementation and Control of Grid Connected AC-DC-AC Power Converter for Variable Speed Wind Energy Conversion System," in Proc. 2003 IEEE Applied Power Electronics Conference and Exposition[C], pp, 154-158.

[7] Patrick S, Flannery, Giri Venkataramanan, et al. A Fault Tolerant Doubly Fed Induction Generator Wind Turbine Using a Parallel Grid Side Rectifier and Series Grid Side Converter. IEEE Trans. on Power Electronics[J], 2008, 23(3): 1126-1135.

[8] Johan Morren, Sjoerd W. H. de Haan,et al. Ridethrough of wind turbines with doubly-fed induction generator during a voltage dip. IEEE Trans. on energy conversion[J], 2005, 20(2): 435-441. 